\title{
Correction to: Automation in Agriculture by Machine and Deep Learning Techniques: A Review of Recent Developments
}

\section{Muhammad Hammad Saleem ${ }^{1}$ (D) Johan Potgieter ${ }^{2} \cdot$ Khalid Mahmood Arif $^{1} \mathbb{D}$}

Published online: 21 June 2021

(C) Springer Science+Business Media, LLC, part of Springer Nature 2021

\section{Correction to: Precision Agriculture https://doi.org/10.1007/s11119-021-09806-x}

The original version of this article unfortunately contained mistakes. The presentation of Figs. 6, 7, 8, 9 was incorrect. The correct versions are given below.

The original article has also been corrected.

The original article can be found online at https://doi.org/10.1007/s11119-021-09806-x.

Khalid Mahmood Arif

k.arif@massey.ac.nz

1 Department of Mechanical and Electrical Engineering, School of Food and Advanced Technology, Massey University, Auckland 0632, New Zealand

2 Massey Agritech Partnership Research Centre, School of Food and Advanced Technology, Massey University, Palmerston North 4442, New Zealand 
Performance comparison of ML/DL models for plant disease and plant recognition applications

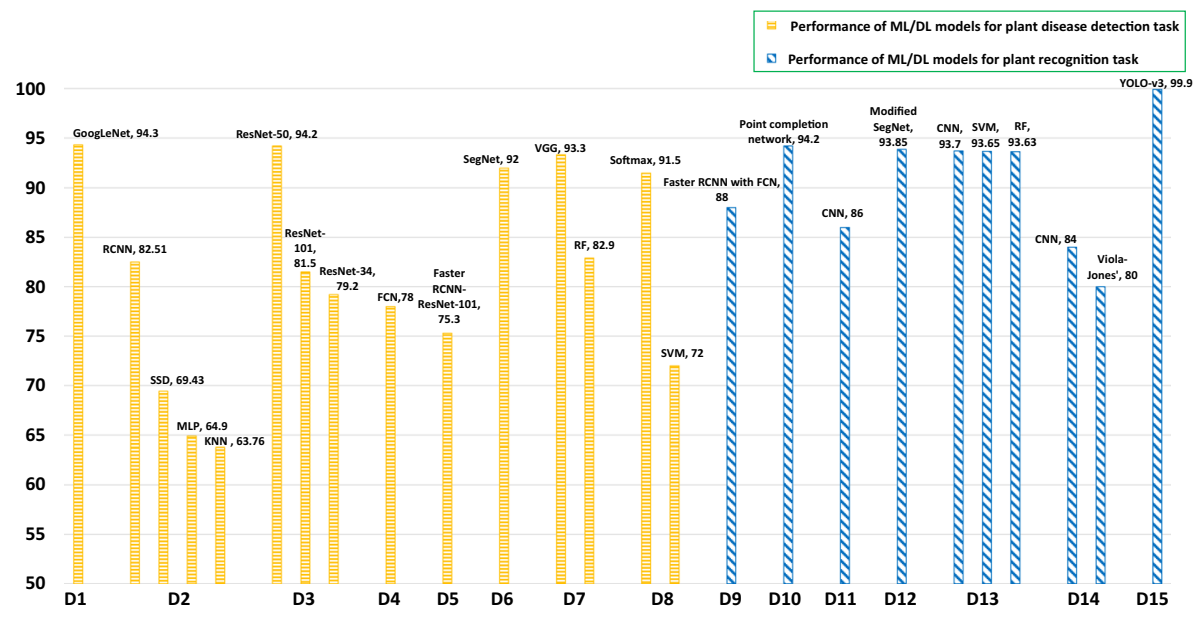

Fig. 6 Performance plots (in \%) of ML/DL models used in robotic systems for plant disease detection (horizontal bars) and plant recognition (diagonal bars) tasks

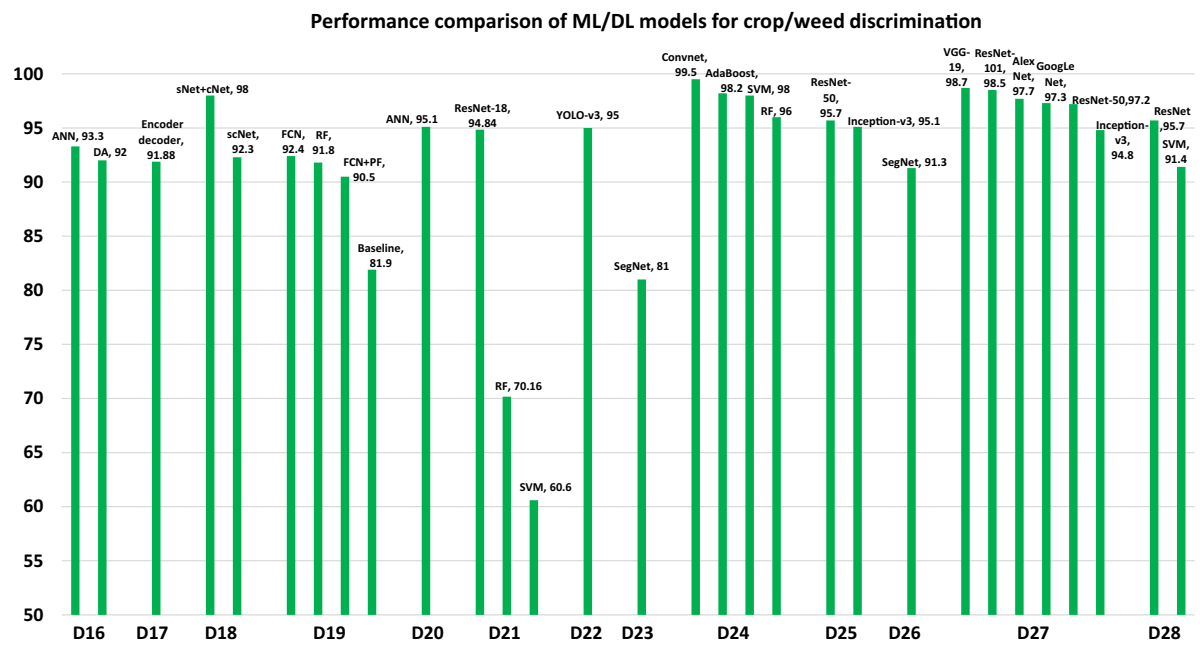

Fig. 7 Performance plots (in \%) of ML/DL models used in robotic systems for crop/weed discrimination task 


\section{Performance comparison of ML/DL models for fruit recognition/harvesting}

100

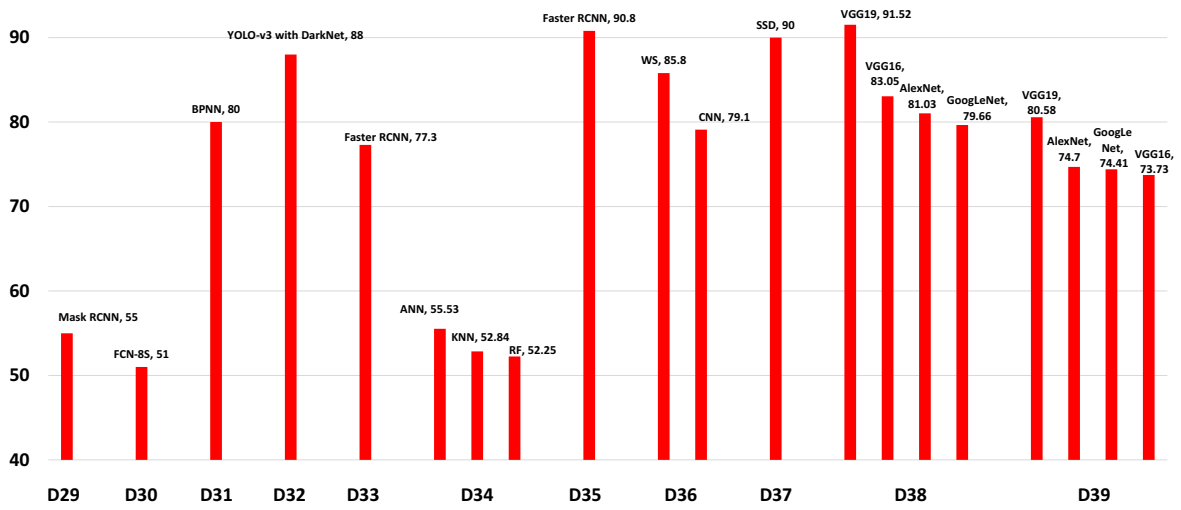

Fig. 8 Performance plots (in \%) of ML/DL models used in robotic systems for fruit recognition and harvesting tasks

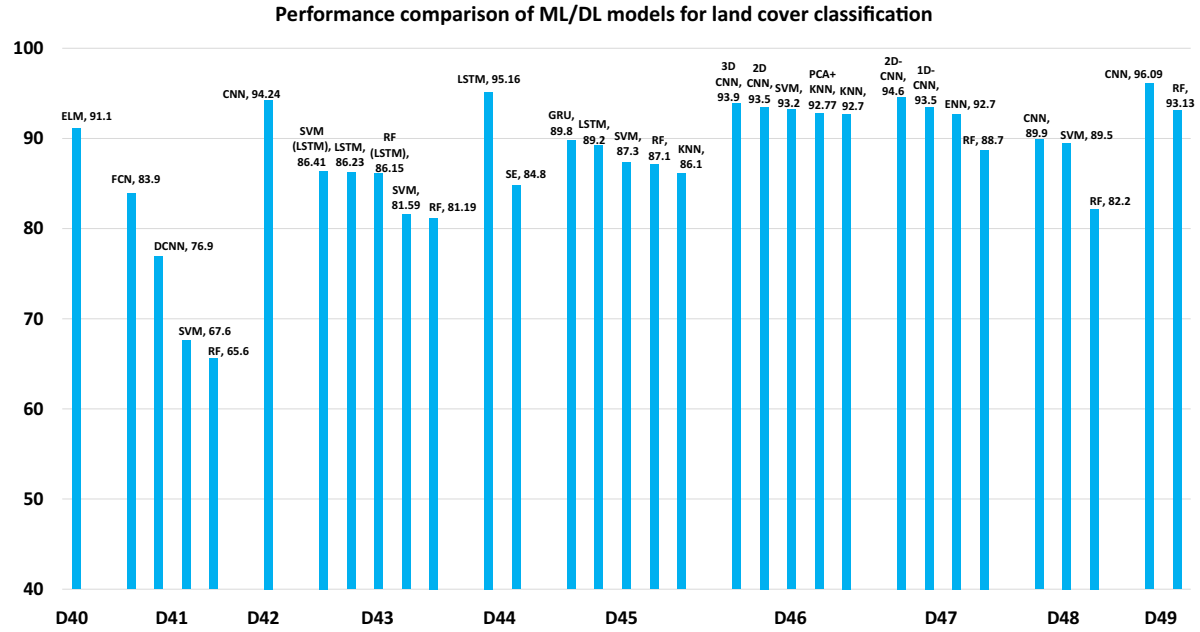

Fig. 9 Performance plots (in \%) of ML/DL models used in robotic systems for the land cover classification

Publisher's Note Springer Nature remains neutral with regard to jurisdictional claims in published maps and institutional affiliations. 